\title{
APSICOLOGIA \\ ARGUMENTO \\ doi: http://dx.doi.org/10.7213/psicolargum.35.88.23360 \\ Mobilização subjetiva e estratégias defensivas de trabalhadores metalúrgicos à luz da Psicodinâmica do Trabalho
}

Subjective mobilization and defensive strategies of metallurgical workers in the light of Psychodynamics of Work

[a] Mestra em Psicologia Clínica pela Universidade do Vale do Rio dos Sinos - UNISINOS; Professora da Escola Superior de Criciúma - ESUCRI/SC, e-mail: silvinhapsico@gmail.com

[b] Doutora em Psicologia Clínica pela Universidade do Vale do Rio dos Sinos - UNISINOS; Coordenadora e Professora do Curso de Psicologia da Faculdade Cenecista - CNEC em Bento Gonçalves - RS; Professora dos Cursos de Administração, Tecnólogo em Recursos Humanos e Licenciatura em Pedagogia da Faculdade Murialdo -FAMUR em Caxias do Sul-RS, Brasil, e-mail: genesispsi2017@gmail.com

[c]] Graduanda de Psicologia da UNISINOS, São Leopoldo/RS, Brasil, e-mail: patricia_henrich@hotmail.com

[d] ] Doutora em Psicologia pela Universidade Federal do Rio Grande do Sul - UFRGS; Professora do curso de Psicologia e do Programa de Pós-Graduação em Psicologia da Universidade do Vale do Rio dos Sinos UNISINOS, São Leopoldo/RS, Brasil, e-mail: janinekm@unisinos.br

\section{Resumo}

O trabalho metalúrgico é antigo na história e de suma importância para a evolução tecnológica. Mesmo com a melhora das condições de trabalho, continua sendo marcado por riscos à saúde física e mental. Este 
estudo objetivou analisar a mobilização subjetiva e as estratégias defensivas de trabalhadores diante do sofrimento psíquico no trabalho metalúrgico de uma indústria no sul do Brasil, segundo a Psicodinâmica do Trabalho. A metodologia empregada possui delineamento qualitativo exploratório-descritivo e a coleta foi realizada através de grupo focal. Participaram sete trabalhadores da indústria. Para a análise dos dados, utilizou-se a análise de conteúdo de Bardin. Os conteúdos expressos nas falas dos trabalhadores indicam que na organização do trabalho desta indústria existe um conjunto de regras e sistemas que a diferenciam da maioria de indústrias do setor - um exemplo é a utilização de uma hierarquia não convencional chamada "chefe zero". Tais particularidades têm garantido experiências bem peculiares no que concerne às vivências de prazer e sofrimento laboral. Destacamos a mobilização do grupo, os modos como articulam suas responsabilidades laborais e a forma que apoiam a formação de mecanismos de proteção para os eventos da organização. O grupo descreve que é muito comum a articulação dos colegas para o cumprimento de metas na organização e também para o processo de adaptação dentro da organização. Tais elementos possibilitam levantar hipóteses de que modelos de gestão pautados no toyotismo podem representar novas formas de sofrimento, mas também, gerar alternativas benéficas à promoção de saúde laboral.

Palavras-chave: Saúde do Trabalhador; Psicodinâmica do Trabalho; Metalúrgica, Saúde e Segurança no Trabalho.

\section{Abstract}

Metallurgical work is ancient and of great importance for technological evolution. Even with the improvement of working conditions, physical and mental health risks remain. The objective of this study is to analyze the subjective mobilization and the defensive strategies of workers in the face of the psychic suffering in the metallurgical work of an industry in the south of Brazil, according to the Psychodynamics of Work. The methodology used has qualitative exploratory-descriptive design and the collection was done through a focal group. Seven industry workers participated. For the data analysis, the Bardin content analysis was used. The contents expressed in the workers' statements indicate that in the work organization of this industry there is a set of rules and systems that differentiate it from most industries in the sector - an example is the use of an unconventional hierarchy - called "zero boss". These particularities have guaranteed very peculiar experiences in what concerns the experiences of pleasure and labor suffering. We highlight the mobilization of the group, the ways they articulate their work responsibilities and the way they support the formation of protection mechanisms for the organization's events. The group describes that peer articulation is very common for meeting organizational goals and also for the process of adaptation within the organization. These elements make it possible to hypothesize that management models based on toyotism may represent new forms of suffering, but also generate beneficial alternatives for the promotion of occupational health.alth; Psychodynamics of Work; Metallurgy, Health and Safety at Work.

Keywords: Worker's Health; Psychodynamics of Work; Metallurgy, Health and Safety at Work.

\section{Introdução}

O mundo do trabalho, em geral, vem sendo marcado por importantes transformações, especialmente no que se refere ao modo de vivenciar a experiência laboral. Na era industrial, contava-se com modelos de gestão que exigiam mais mecanicidade e força física do corpo trabalhista do que cognição. A capacidade de criação e o envolvimento emocional não eram valorizados como habilidades fundamentais e, sim, o quanto o sujeito conseguia fornecer a mão de obra braçal no manuseio de máquinas e equipamentos fabris. Tais características eram típicas do taylorismo e fordismo. Com o passar dos anos e com as novas necessidades evidenciadas na sociedade pós-moderna, os modelos mecanicistas precisaram incrementar suas formas de trabalho e, consequentemente, os sujeitos absorverem tais mudanças (Heloani \& Capitão, 2003). Dentre as características que foram mudando, destaca-se as exigências de um trabalhador flexível, polivalente e pró-ativo, buscando uma reinvenção de si (Silva, 2008), que cuide de seu cronômetro (Antunes, 2001) para a sobrevivência dentro 
das organizações. A partir dessas mudanças, o foco de investimento operacional passa para o intelectual e subjetivo, ou seja, para o modelo japonês toyotista.

Este trabalho busca abordar a mobilização subjetiva e as estratégias defensivas dos trabalhadores diante do sofrimento psíquico no trabalho metalúrgico de uma indústria, a qual prioriza modelos de gestão pautados em qualidade total e pressupostos toyotistas, a partir da abordagem da Psicodinâmica do Trabalho (PdT). Partindo disso, pretende-se descrever como os trabalhadores deste setor se mobilizam em prol da saúde mental, bem como analisar quais são as estratégias defensivas e de enfrentamento utilizadas por eles.

Dentro deste contexto de trabalho, este estudo privilegia o setor metalúrgico por sua representatividade no contexto brasileiro. Os trabalhadores metalúrgicos representam mais de 5\% do total dos empregos formais no País, segundo dados da Relação Anual de Informações Sociais - RAIS (Brasil, 2011). O setor é um dos mais importantes da economia nacional, por concentrar grande parte da evolução tecnológica, a partir da transformação do aço e seus derivados, participando da sua construção e contribuindo política e economicamente para o país (Dieese, 2012).

As pesquisas realizadas no setor metalúrgico demonstram que, apesar das mudanças que ocorreram pós-revolução industrial, existe uma prevalência de modelos clássicos de gestão, marcados por trabalhos repetitivos e insalubres. Para a revisão de literatura, buscaram-se bases de dados nacionais e internacionais, em especial a Academic Search Elite e Medline com os termos "metallurgy and psychology". Vale destacar que o setor metalúrgico abrange muitos descritores e termos associados. Nesta pesquisa, não houve o intuito de sistematizar e sim de valorizar artigos que contribuíssem com a proposta do estudo.

Nos achados, constatou-se que, em âmbito internacional, o estresse em trabalhadores metalúrgicos é uma temática recorrente (Falco, Girardi, Marcuzzo, De Carlo, \& Bartolucci, 2013; Padula, Chiavegato, Cabral, Almeida, Ortiz, \& Carregaro, 2012; Rabe, Giacomuzzi \& Nubling, 2012). As doenças ocupacionais com lesões (Bouchardet al., 2007; Hensing \& Alexsanderson, 2004; Blond, Netterstrom \& Louesen, 2007) e as exigências organizacionais, como perfis e carga de trabalho (Tuomi, Vanhala, Nykyri, \& Jonhomen, 2004) também englobam estudos sobre o setor fabril. Tuomi et al., (2004) investigaram o contexto organizacional a respeito do impacto no cotidiano dos trabalhadores e destacaram a relevância de investir no trabalhador e em seu bem-estar como diferenciais à produtividade e ao comprometimento.

O artigo intitulado Desenhando a nova morfologia do trabalho no Brasil, de Antunes (2014), revisita três estudos sobre o trabalho no Brasil, analisando as consequências das formas de gestão emergentes, surgidas nas décadas de 1990, no mundo do trabalho. Segundo o autor, estas mudanças refletem em novas configurações trabalhistas e novas formas de sofrimento e exploração. Dentre os estudos levantados, um, em especial, aborda o setor automotivo nacional, destacando a intensificação do trabalho no setor metalúrgico, através da redução do "tempo morto", demissões voluntárias e realocação em outras unidades. Tais situações geram redução salarial, padronizações e robotização do processo produtivo diante da crise econômica dos últimos anos. É evidenciada a existência de pressão e medo perante o risco de desemprego. Além disso, é destacada a perversidade nos processos de gestão e o quanto os sujeitos ficam à mercê da realidade posta pelo sistema. Dentre as consequências, 
o número de lesões físicas e o impacto na saúde mental ficam evidentes pelo alto índice de antidepressivos utilizados pelos trabalhadores. O artigo destaca inúmeras mudanças ocorridas na forma de vivenciar o trabalho, demonstrando que tais alterações ocorreram em todos os setores de trabalho no Brasil, do campo industrial ao trabalhador rural (Antunes, 2014).

Em relação à saúde mental, temática fundamental para a Psicologia, a PdT é uma abordagem que auxilia no debate promissor do que é saúde e do que é capaz de promover saúde mental no contexto laboral. Dejours $(1997 ; 2001 ; 2007 ; 2008 a)$, sugere que trabalhar é um inevitável confronto entre o sujeito e a organização de trabalho (OT), sendo assim, constantemente uma luta contra o sofrimento. O sujeito necessita mobilizar seus recursos subjetivos para conseguir transcender a vivência laboral árdua e transformar o sofrimento em prazer (Moraes, 2013).

Esse sofrimento pode ser categorizado como patogênico ou criativo (Dejours, 2009). O primeiro é causado quando o sujeito não consegue transformá-lo ou ressignificá-lo, devido à ausência de flexibilidade da OT, que impede que o sujeito encontre vias de descarga pulsional. E o criativo depende da mobilização do sujeito para criar novas soluções na transformação do sofrimento em algo benéfico para si próprio. Para ampliar seus mecanismos de enfrentamento o sujeito necessita encontrar alguma possibilidade de liberdade na OT, a qual pode ser potencializada por espaços de discussão, cooperação e inteligência prática, para negociar entre as imposições organizacionais e o desejo do trabalhador.

A clínica do trabalho propicia o entendimento das formas como os trabalhadores agem frente às dificuldades e sofrimentos gerados diante do distanciamento entre prescrito e o real do trabalho. Desta forma, busca-se agenciar uma discussão a partir das vivências de trabalho, onde os sujeitos podem falar e elaborar suas angústias e sofrimentos (Mendes \& Vieira, 2014).

Os espaços de escuta e debate se tornam fundamentais para compartilhar os sentimentos vivenciados no trabalho, fazendo com que o sujeito nomeie o sofrimento, e busque possibilidades de ressignificá-lo e transformá-lo em prazer. Esse processo torna-se essencial, uma vez que é no trabalho e através dele que é construída a subjetividade e o lugar social. Os autores Heloani e Lancman (2004) reforçam a ideia da centralidade do trabalho na constituição da identidade, além de elucidar sobre a sua implicação social para os sujeitos.

A PdT é uma abordagem teórico-prática que se alinha à clínica do trabalho, com princípios que oportunizam a promoção do espaço de discussão sobre o coletivo laboral (Martins \& Mendes, 2012). Dejours (2004) preconiza que o sujeito vivencia as relações de trabalho e com o trabalho, a partir de um processo dinâmico de sofrimento e prazer, caracterizado pela evitação do sofrimento e a busca de prazer. Essa dinâmica é resultado do enfrentamento do sofrimento, seja pelo uso de estratégias defensivas, que visam à negação ou a diminuição do sofrimento, seja pela mobilização subjetiva, que ajuda visa transformar as situações geradoras de sofrimento em situações de prazer (Dejours, 2004). O fracasso na utilização das estratégias defensivas e de enfrentamento pode levar ao adoecimento do indivíduo no trabalho (Mendes, Costa, \& Barros, 2003). 
A mobilização subjetiva se dá pelo engajamento interno do sujeito e sua subjetividade frente às experiências significativas com os pares e a gestão. Esta relação simbólica depende do coletivo de trabalho e do modo como este é percebido e autorizado dentro do contexto laboral (Mendes \& Duarte, 2015). Ela emprega a inteligência prática, a capacidade própria e a criatividade do trabalhador diante de situações imprevistas no mundo do trabalho.

A cooperação é uma estratégia que mobiliza o grupo para o prazer ou para a defesa do sofrimento (Bueno \& Macêdo, 2012, p.313). O que importa à cooperação é "a liberdade dos indivíduos e formação de uma vontade coletiva", a qual supõe esforços de inteligência e de participação legítima da corporação laboral (Lancman \& Sznelwar, 2004, p.67).

Nesse processo, a cooperação, a inteligência prática, os espaços de discussões e o reconhecimento dos pares e da gestão representam conceitos genuínos de uma mobilização subjetiva significativa para a saúde mental dos trabalhadores. Em contrapartida, a ausência de espaços para transformação do prescrito, diante do real, e a opressão da gestão sobre o trabalhador, contribuem para a criação de estratégias defensivas que servem para amenizar o sofrimento (Fleury \& Macedo, 2015). As estratégias defensivas são condutas elaboradas pelos trabalhadores como forma de suportar o sofrimento patogênico, sem que o trabalhador adoeça (Mendes, 2007).

Diante das questões apresentadas, este trabalho teve por objetivo analisar a mobilização subjetiva e as estratégias defensivas de trabalhadores diante do sofrimento psíquico no trabalho metalúrgico de uma indústria situada no sul do Brasil.

\section{Método}

Esta pesquisa tratou-se de um estudo exploratório-descritivo (Creswell, 2010).

\section{Participantes}

O estudo contou com a participação de sete trabalhadores de uma organização de trabalho metalúrgica, situada no sul do Brasil. Cabe destacar que essa metalúrgica abrange modelos de gestão de qualidade total, como a OSHAS 18001, o qual privilegia a sustentabilidade e a saúde e segurança no trabalho. Os princípios e critérios para a adesão e reconhecimento da norma são bastante peculiares, por contar com auditorias frequentes e exigências prescritas de segurança e saúde laboral (Haviland, Burns, Gray, Ruder, \& Mendeloff, 2010).

Destacam-se as seguintes características do grupo participante: a maioria era do sexo masculino (seis homens e uma mulher), com idades entre 22 e 42 anos, tempo de trabalho que variava de dois a nove anos, a maior parte deles tinha escolaridade correspondente ao nível superior incompleto e, em menor parcela, ensino técnico completo. Além disso, nenhum dos participantes relatou ter vivenciado incidente ou doença relacionada ao trabalho durante o período em que atua nesta empresa.

Constituiu-se como critérios de inclusão na pesquisa: ser trabalhador do setor operacional de uma organização metalúrgica específica, com mais de seis meses de contrato na CLT. E como critérios de exclusão: estar participando, na época da pesquisa, da gestão, do CIPA ou ser Técnico de Segurança do Trabalho. 


\section{Instrumentos e técnicas}

Um questionário sociodemográfico foi utilizado para caracterizar o grupo investigado. Nele estavam contidas informações como: idade, sexo, escolaridade, tempo de trabalho, características sobre trabalho, possíveis acidentes, lesões ou doenças decorrentes do trabalho.

Também foi utilizada a observação participante, tendo como características a interação e o registro das informações do ambiente analisado. O pesquisador, através de sua percepção e olhar, busca compreender o universo observado, aprendendo com o ambiente e discutindo o seu contexto (Flick, 2009). Esta técnica foi registrada em um diário de campo (Hess, 1998).

O procedimento do grupo focal, neste estudo, consistiu na realização de dois encontros com os mesmos participantes, a fim de explorar informações relevantes para responder aos objetivos e validar o material coletado. Para este recorte da pesquisa, utilizouse a seguinte questão: "O que vocês fazem para lidar com dificuldades presentes no dia-adia de trabalho?"

Segundo Barbour (2009), os grupos focais são uma maneira eficaz de desvendar o modo como os participantes pensam, além de refletir questões e preocupações importantes para o grupo, relativo ao contexto investigado. Os grupos focais têm sido empregados como uma possibilidade de adaptação do método stricto senso em pesquisa com orientação teórica da PdT, desenvolvida por Dejours. A metodologia original da PdT tem limitações de ordem prática e temporal, visto que a disponibilidade da utilização de vários encontros (de cinco a oito) em grupos vinculados ao setor privado é reduzida. (Monteiro, Giongo, \& Castro, 2015; Giu, 2002).

\section{Procedimentos Éticos e de Pesquisa}

A indústria investigada mostrou-se disponível para parceria do estudo. Num primeiro contato com o gestor este verbalizou (registro de diário de campo) que desejava que a organização fosse uma indústria de aplicação - vínculo fomentado por diversas parcerias com universidades. Com os trabalhadores, foi realizado o primeiro contato em uma reunião coletiva, e sem a presença da gestão, para apresentar a proposta de pesquisa. Nessa conversa, a pesquisadora falou sobre o projeto, sobre o compromisso social com a saúde do trabalhador e sobre os procedimentos para participação voluntária nos encontros de grupo focal.

Para manifestar o interesse em participar, foi colocado à disposição, fichas para preenchimento de dados pessoais, como telefone e e-mail, para posterior contato. Tal ação, com o intuito de tirar dúvidas e relatar os detalhes e as possíveis datas para o primeiro encontro do grupo focal. Nesta ligação, alguns manifestaram dificuldades em estar presente na data agendada (nove desistiram no agendamento) e 12 comprometeram-se em comparecer. Na data estimada para o primeiro encontro, sete compareceram. O período da coleta de dados ocorreu entre os meses de outubro de 2014 e março de 2015.

A escolha do local e horário para realizar o primeiro encontro foi feita de modo a beneficiar o deslocamento dos voluntários e representar um local neutro. Optou-se por um espaço fora da empresa, logo após o horário de trabalho e com duração de $2 \mathrm{~h}$. A 
pesquisadora ofereceu ressarcimento dos gastos com deslocamento e lanche após o encontro. Nesta ocasião, houve a participação de uma co-coordenadora participante do grupo de pesquisa.

O segundo encontro, datado conforme tratativas com o grupo, teve como propósito validar os dados obtidos no primeiro encontro. Realizou-se uma discussão sobre o conteúdo emergido e examinou-se se existiam questões que eles desejariam complementar. A pesquisadora optou por trazer uma primeira análise dos dados (realizada com supervisão da orientadora) e ler algumas falas selecionadas.

Foram observados os parâmetros éticos da pesquisa com seres humanos da Resolução 466/2012. O projeto foi submetido ao Comitê de Ética em Pesquisa da Universidade (CEP $\mathrm{n}^{\mathrm{o}}$ 14/132), bem como os trabalhadores receberam informações sobre todos os procedimentos de pesquisa no primeiro encontro do grupo focal - dentre as informações descritas, destaca-se a permissão do grupo para gravação do áudio da conversa. O Termo de Consentimento Livre e Esclarecido - TCLE se deu através da leitura e assinatura, estando todos cientes sobre a liberdade de desistir da participação na pesquisa, sem nenhum prejuízo. As falas foram registradas através de gravação de áudio e, posteriormente, transcritas. Todo o conteúdo manifesto foi considerado fala do grupo e não individual. Ao final dos encontros, a pesquisadora ficou disponível para orientações individuais e eventuais necessidades dos trabalhadores.

\section{Procedimentos de Análise dos Dados}

Para tratamento dos dados, foi utilizada a análise de conteúdo, de acordo com os pressupostos de Bardin (2011). A partir da transcrição, a análise ocorreu em dois momentos: primeiramente foi realizada uma leitura minuciosa, para apropriação do conteúdo e, no segundo momento, buscou-se categorizar as falas do grupo, utilizando categorias a priori, a partir do referencial teórico da PdT.

Posteriormente, o material foi analisado por duplos juízes do grupo de pesquisa para avaliar a concordância na categorização realizada. Tal técnica resultou numa concordância de $82,6 \%$. Em algumas falas onde ocorreu discórdia foi utilizado um terceiro juiz para estabelecer um consenso.

\section{Resultados e discussão}

A discussão e os resultados deste estudo visaram abordar a mobilização subjetiva e as estratégias defensivas utilizadas pelos trabalhadores diante do sofrimento psíquico no trabalho metalúrgico de uma indústria, a qual priorizava modelos de gestão do toyotismo. Pretendeu-se descrever como os trabalhadores se mobilizaram em prol da saúde mental, bem como analisar quais foram as estratégias defensivas e de enfrentamento utilizadas pelos trabalhadores. Vale destacar que o trabalho seguiu os pressupostos da PdT. A seguir serão descritas, as categorias e subcategorias organizadas a partir das falas, vide tabela 1. A categoria de Mobilização Subjetiva agrupou subcategorias descritas como: enfrentamento, inteligência prática, cooperação, espaços de discussão e reconhecimento, enquanto a categoria Estratégia Defensiva não obteve subcategorias. 
Tabela 1

Categorias de análise dos dados

\begin{tabular}{ll}
\hline Categoria & Subcategoria \\
\hline Estratégia Defensiva &
\end{tabular}

Estratégia Defensiva

Mobilização Subjetiva

Enfrentamento

Inteligência prática

Cooperação

Reconhecimento

Espaços de discussão

\section{Estratégias Defensivas}

O conceito de Estratégias Defensivas foi desenvolvido por Dejours (2003) ainda no primeiro livro do autor, A Loucura do Trabalho. Os conceitos de estratégias, advindo da Psicanálise, e de seus mecanismos de defesa do ego, apesar de não serem iguais, aproximamse teoricamente. Estratégias defensivas são maneiras que o sujeito ou grupo buscam para lidar com o seu sofrimento, aliviando e normalizando sua situação emocional diante das situações precárias, rígidas e contraditórias de trabalho. A grande questão que vai impactar nas diferenças entre estratégia defensiva e de enfrentamento é que a primeira não ataca a causa e pode levar o sujeito à alienação ou ser ineficaz com o tempo, e transformar-se em patologia; e a segunda mobiliza o sujeito ou grupo a ter uma atitude ativa, transformando o sofrimento em criativo (Bueno \& Macêdo, 2012; Mendes \& Vieira, 2014).

A indústria pesquisada tem uma cultura que se difere da maioria no ramo metalúrgico. Por essa razão, torna-se natural uma resistência inicial de novos funcionários ao modelo de gerenciamento aparentemente aberto e livre de um sistema hierárquico, denominado de "chefe zero". Tal sistema, que incentiva a autonomia produtiva, é descrito pelos trabalhadores como o ponto mais crítico para adaptação.

Uma estratégia defensiva utilizada diante do sofrimento de ter que adaptar-se a ausência de um chefe e a existência de uma cultura que não tem uma pessoa controlando seu trabalho é a negação, subentendida nos relatos. Este funcionamento da empresa é sentido como algo estranho e impraticável dentro de uma organização: "Tem alguma pegadinha aí". Todos os trabalhadores do grupo evidenciaram ter passado por este conflito no início de seus vínculos de trabalho com a X. "Não, não. Pra mim foi o erro, nesses primeiros 20, 30 dias, foi, mas não, não, isso aí tá errado '- No terceiro (mês)... ' ‘a gente muda... ’”. E, tal sofrimento leva os trabalhadores a um dilema de mudar (enfrentando essa situação) ou abandonar o trabalho (desistência do trabalho): "Então vai chegar um momento onde tu vai ter que parar, ou tu vai se adaptar automaticamente, ou tu vai procurar o teu espaço".

Ainda na categoria "Estratégias defensivas", foi analisada a utilização da projeção. Tal mecanismo é relacionado ao conflito vivido pelo grupo de trabalhadores quanto ao modelo "chefe zero", que não fomenta o controle de trabalho por um representante hierárquico superior, e sim, uma referência técnica, apenas para dúvidas de procedimentos 
laborais: "É que não tem quem cobre, não tem lá o fulano grandão - tá me cuidando! Não tem lá na empresa, então cada uma acha que cada um é dono de seu nariz". No diálogo dos participantes, fica subentendido que existe uma tendência do coletivo de trabalho em projetar algumas cobranças, relacionadas à disciplina e ao andamento do trabalho, como algo de responsabilidade do grupo. Ou seja, uma cobrança coletiva substituindo a cobrança do hierárquico superior. As normas, que são flexíveis para a OT, tornam-se alvo de controle de pares e não da gestão: "Só de ouvir falar "oh fulano, olha só...” Mas não de cobrar assim, só na brincadeira, no tom de brincadeira, aquela risada amarela que se diz... mas de cobrar "bah fulano, tu tá até as 7:30 lá no café".

Tais mecanismos podem minimizar conflitos com a gestão, mas por outro lado podem favorecer relações de trabalho perversas entre os pares, e ocasionar um vínculo de desconfiança, danosos à saúde mental dos trabalhadores: "eu acho uma baita falta de respeito com os colegas, que tomaria às $7 \mathrm{~h}$ (o café), no seu horário certo. Não tem ninguém que chega nele e vai dizer" (trabalhador referindo-se a um colega que costuma tomar café mais tarde).

Destaca-se que as estratégias de defesa relatadas nesse estudo como a negação a projeção, apesar de serem estratégias presentes em outros grupos investigados em pesquisa utilizando a PdT (Giongo, Monteiro, \& Sobrosa, 2015), não foram localizadas essas estratégias com características semelhantes às relatadas aqui. A estratégia de negação, por exemplo é mais utilizada no sentido de negar o sofrimento vivenciado no trabalho. Talvez isso se deva a OT própria da instituição estudada, a qual possui características peculiares e não tão convencionais como o uso do "chefe zero" e uma maior liberdade para gerenciar o tempo no trabalho.

\section{Mobilização Subjetiva}

Mobilização subjetiva é quando o trabalhador consegue utilizar de seu conhecimento subjetivo para agregar ao trabalho o seu conhecimento prático - através da criatividade, saber-fazer e da inteligência prática (Moraes, 2013). A mobilização subjetiva envolve um processo que se utiliza dos recursos psicológicos e espaços públicos de discussão buscando a solução de conflitos inerentes ao trabalho, transformando a experiência de sofrimento em prazer (Mendes, 2007). Para tanto, são fundamentais a existência de elementos como: a inteligência prática, a cooperação, o reconhecimento e espaços de discussões (sub categorias abordadas neste estudo). Além disso, a estratégia de enfrentamento (subcategoria) pode ser entendida como um tipo de mobilização subjetiva.

Enfrentamento

O enfrentamento pode ser entendido como algo que procura modificar o que gera sofrimento. É quando o trabalhador consegue reconhecer aquilo que gera o sofrimento e age para alterar a origem do problema (Moraes, 2013; Ramos \& Mendes, 2013). É diferente de estratégia de defesa. O enfrentamento é um tipo de mobilização subjetiva. O seu conceito está dentro da Mobilização Subjetiva, o contrário não. 
Atitudes que fomentem um pensamento crítico diante do prescrito de trabalho representam uma forma de enfrentamento importante para a saúde mental de trabalhadores. Este potencial é a forma mais eficaz de lidar com sofrimento ou canalizar a energia para manter a saúde mental e pode ser praticado de diversos modos (Vieira, 2014). Dentro do grupo analisado, é verbalizado que existem espaços para expressar suas angústias e questionar alguns procedimentos, podendo contrariar eles quando necessário: "Ah, eu não me sinto seguro porque eu acho que não vai dar certo. 'Tu tem a liberdade"” (de não fazer).

A OT estudada fomenta a liberdade de acesso aos mais diferentes setores e pessoas da empresa, o que autoriza o enfrentamento: "E a gente pode ir até lá, pode ir até o fulano, a gente consegue conversar, a gente consegue falar com o beltrano que é o dono da empresa, sabe", "todo mundo tem diálogo com todo mundo". Uma forma de lidar ou enfrentar os conflitos e imprevistos no contexto de trabalho é potencializada pelo conhecimento de tudo que ocorre na OT. "Todo mundo sabe as coisas que acontecem lá, as coisas boas e ruins né". Além de responsabilizar a todos pelo que acontece na rotina laboral e assumir os riscos. "Depois de um tempo todo mundo sabe qual o seu compromisso, o que tem que fazer, o que não tem e o que precisa, ou não precisa".

Inteligência Prática

A inteligência prática, compreendida pela capacidade do trabalhador em imprimir sua marca na obra desenvolvida (Moraes, 2013), está relacionada à audácia do trabalhador em transformar o prescrito no real, utilizando sua reflexão e pensamento para elaborar, engendrar aquilo (Vieira, 2014; Duarte \& Mendes, 2015).

Esse processo pode ocorrer devido à realidade de trabalho que propicia espaços de inteligência prática. "Tu pode modificar, se eu acho que 'Ah, não, essa ferramenta não tá boa assim, eu vou lá e pego outra ferramenta e boto. Se esse eixo não tá sendo feito assim eu vou lá e troco"'. É confiado ao sujeito autonomia, onde o mesmo desenvolve o seu potencial, partindo daquilo que ele acredita ser o mais adequado para o desempenho do trabalho. "Desse jeito, essa máquina, desse jeito aqui eu não... 'Eu já tropiquei umas três vezes nessa alça ali', daí ela vai lá, analisa e daí fazem a mudança né”. Assim como não são os gestores quem ditam as formas de desenvolver o trabalho, mas é o trabalhador que tem o domínio do desempenho do trabalho: "No caso é o operador que vê, tipo, que tá todo dia ali né, que vive ali no..." (referindo-se ao maquinário de trabalho).

$\mathrm{Na} O \mathrm{OT}$ investigada, os trabalhadores assumem o domínio e o manejo do trabalho com responsabilidade e autonomia. A cultura fomentada pelo "chefe zero", contraditório nos sentimentos gerados no grupo, parece elucidar uma apropriação do trabalho real em detrimento do prescrito. A liberdade percebida propicia uma leitura salutar do pertencimento e manejo prático: "A pessoa, é a mesma coisa que tu varrer o chão, tu vai varrer todo dia vai saber o que se deve. Não vai ser a pessoa lá de dentro do RH que vai saber curtir o que tá errado e o que que não tá, né".

$\mathrm{Na}$ relação do grupo de trabalho, o aspecto de liberdade e tempo disponível foi levantado como fundamental para a proteção e segurança laboral: "Eu acho que até ocorre menos acidentes porque não tem aquela cobrança, de bah, tu tem que produzir. Porque ali tu tem tempo de raciocinar, tu analisar". Esses espaços, com maior autonomia para dar o 
ritmo de trabalho e para fazer a gestão do tempo, podem gerar reflexões e maior entendimento dos processos de trabalho, mobilizando os trabalhadores à compreensão de normativas, que em outros contextos poderiam ser automatizadas e sem sentido. A alienação é um conceito trabalhado por Dejours (2004) sobre a falta de oportunidade que os trabalhadores, e mesmo a gestão, têm de estabelecer relação com o real do trabalho, dificultando ou impossibilitando o reconhecimento dos riscos no contexto. Na indústria investigada, infere-se que há essa reflexão e é através da inteligência prática que os sujeitos conseguem pensar sobre os modos de fazer-laborais, protegendo e relacionando-se de modo salutar: "a norma, pelo menos pra mim, ela existe, eu sei que ela tem que ser cumprida e tudo mais. Nela em si, se ela não existisse entre nós não ia deixar de ser cumprida".

\section{Cooperação}

Para Dejours (2004), a cooperação se dá a partir do desejo das pessoas em estarem juntas, trabalhando e superando as contradições presentes no contexto laboral. A vontade coletiva é um fator que não pode ser prescrito e depende da liberdade conquistada no contexto laboral. Para esta relação de cooperação, é preciso que a confiança faça sentido, através de acordos e normas que favoreçam este reconhecimento (Duarte \& Mendes, 2015).

Alguns relatos indicaram a existência da cooperação na execução de tarefas. "E aí tu começa a conversar com um e com outro, e aí tu troca as informações, 'e não é assim' e tu começa..."; "Então se o sujeito faltar, ele vem, dá pra dar uma liberada lá? Falta pouquinha coisa né, bah, dá uma acelerada aqui só pra nós". Essa atitude é fundamental para que se estabeleça um coletivo de trabalho. No caso da empresa estudada, a proposta de gestão, baseada nos pressupostos toyotistas e de funcionamento por ilhas dependentes de trabalho (Antunes, 2014), convoca os trabalhadores para uma prática cooperativa: "O tempo de um é o tempo de outro". Essa prática colaborativa pode acontecer porque ela é percebida pelo coletivo de trabalho como algo valorizado e autorizado no contexto laboral (Mendes \& Duarte, 2013).

A colaboração ocorre no grupo como um todo, propiciando um espaço coletivo de trabalho, instigando o desenvolvimento conjunto: “[...] tu vai participando e crescendo junto com aquele crescimento [...] Que envolve todos né, não é só 2, 3”. Para Mendes (2007), o coletivo de trabalho pressupõe a equidade, a confiança e a solidariedade, bem como a valorização do esforço conjunto na realização da tarefa.

Reconhecimento

O reconhecimento pressupõe uma valorização das atitudes e prática laborais, por parte da gestão e/ou colegas de trabalho. Envolve o julgamento dos colegas (julgamento da beleza) e/ou a percepção de utilidade dentro do trabalho desenvolvido (julgamento da utilidade). Para Mendes (2007, p.45), o reconhecimento "é um dos modos de fortalecimento da estrutura psíquica e da saúde" mas também complementa que por outro lado, ele "pode ser um modo de captura dos trabalhadores nas armadilhas da dominação" (Idem).

Os trabalhadores trouxeram em seus relatos fatores que demonstram um reconhecimento dentro da indústria pesquisada. No quesito social, são descritos momentos de participação e valorização das opiniões e iniciativas por parte do grupo de trabalhadores. 
A fala "as pessoas dão as sugestões e daí tem toda uma análise e aquela pessoa participa junto né. Pra acompanhar e pra e ver se é viável” demonstra claramente as possibilidades de participação e integração com a gestão da indústria. As ideias são discutidas e analisadas a partir da viabilidade de colocá-las em prática. Além da possibilidade de participar com novas ideias, são evidenciadas no discurso as possibilidades de reaver processos e procedimentos de trabalho, conforme a fala: "lá na X, quem dá sugestões, quem participa dos processos, é as pessoas que tão participando, que tão vivendo aquilo, e elas recebem o respeito por aquilo, elas que recebem o retorno daquilo.".

O coletivo de trabalho contempla a ideia de um grupo de pessoas que encontram um modo de se relacionar socialmente aos compromissos, agregando sentimentos de pertença $\mathrm{e}$ envolvimento com o todo. A construção de sentido advém desta relação e culmina no reconhecimento. $\mathrm{O}$ sujeito cria expectativas para a realização pessoal e é prestigiado entre os pares e a organização. Para Dejours (2004), estas duas ideias colaboram na construção da identidade e no processo de mobilização subjetiva.

A mobilização subjetiva é de uma base frágil e espontânea, necessitando de uma relação de contribuição - retribuição. É necessário que o grupo se sinta reconhecido e tenha oportunidade para significar suas vontades e iniciativas. O contrário gera frustração e riscos eminentes à saúde mental (Dejours, 2004).

Espaços de Discussão

No processo de mobilização subjetiva e coletiva para saúde e segurança no trabalho, os participantes do grupo focal descrevem uma proximidade e a possibilidade de diálogo coletivo tanto entre os pares como com a gestão. Os trabalhadores descrevem haver uma flexibilidade no processo de fiscalização em Sáude e Segurança no Trabalho: "Mas se hoje a técnica de segurança te ver sem o protetor, ela não vai chegar dando advertência nem nada, ela chega e conversa, ela tem a liberdade, ela conversa tudo contigo, sabe". Na percepção do grupo, este processo eleva a conscientização para a mudança. Não se deseja fazer o prescrito por ser obrigação, e sim, porque preserva a saúde "Então hoje a norma, pelo menos pra mim, ela existe, eu sei que ela tem que ser cumprida e tudo mais. Nela em si, se ela não existisse entre nós não ia deixar de ser cumprida".

Além desse fator de conscientização, a proximidade estabelecida com a equipe de segurança denota uma aliança para o cumprimento das normativas. "E não é feito somente pela técnica de segurança, ela vai até o setor, te pergunta o que que tu acha e o que que pode acontecer, o que tu acha que pode acontecer aqui”. Estes espaços de discussão são vivenciados de modo natural entre os setores operacionais e os setores de gestão, uma fala que auxilia no entendimento desta abertura para discussão é "Assim como tem a visão de quem tá de fora, às vezes, o pessoal de lá de dentro do escritório chegar e perguntar: 'Bah, mas isso aí não é perigoso?'. Daí o cara tem a liberdade de explicar: 'Não, é feito assim, assim, assim e não é perigoso, seria perigoso de tal maneira"”.

\section{Considerações Finais}

Na OT estudada, destacou-se que existe certa dificuldade, por parte dos trabalhadores, em buscar auxílio no processo de adaptação à proposta de chefe zero. 
Percebe-se que o grupo de trabalhadores sofre, cria suas formas de lidar com o sofrimento, mas pode não enfrentar ou modificar a origem desse sofrimento. Vivenciar a experiência de não ter ninguém vigiando, com horários flexíveis e liberdade para fazer suas práticas laborais são ações pouco comuns no contexto laboral e, nesta organização, lidar com tais mudanças pode ocasionar mal-estar psíquico.

As estratégias defensivas e de enfrentamento operam nos trabalhadores diante do sofrimento inerente à realidade de trabalho. A manifestação delas pode ser boa ou ruim, dependendo das circunstâncias. As defesas podem ser de proteção, adaptação ou de exploração.

Os dados apontaram que a OT investigada tem possibilitado a mobilização coletiva dos trabalhadores, potencializando a transformação do sofrimento em prazer. Em algumas situações, percebe-se uma tendência à idealização do espaço e da oportunidade de trabalho diferenciado. Tais idealizações podem estar resultando em estratégias defensivas de negação do sofrimento e do que pode estar gerando sofrimento nesta OT. Mendes (2007) aborda que algumas estratégias, quando usadas maciçamente sem modificar a origem do sofrimento, podem virar forma de agir, cristalizando o sofrimento sem dar-se conta da realidade, tornando uma ideologia defensiva. Ou ainda, pode-se mencionar a questão da "captura da subjetividade", proposta por Alves (2008), que nos reforça o quão perversa podem ser algumas ações organizacionais - que envolvem o sujeito ao ponto de fazer seus desejos os objetivos pessoais. $\mathrm{O}$ grupo passa a acreditar naquilo, de modo que a mazela não seja consciente.

O estudo sobre estratégias defensivas e de enfrentamento do modelo chefe zero necessita de mais aprofundamento, uma vez que alguns trabalhadores elucidaram o quanto este movimento de adaptação à cultura de autogerenciamento é problemático, ao ponto de levar algumas pessoas a desistirem do trabalho e depois manifestar arrependimento e interesse em retornar. Uma sugestão para tais questões seria uma nova pesquisa, através de entrevistas, com quem saiu espontaneamente de Organizações, ou desta Organização. Abordar e investigar as entrevistas de desligamentos ou acessar tais pessoas que saem e, muitas vezes, querem voltar. Cabe destacar que os resultados obtidos nessa pesquisa tratamse de uma realidade específica, não sendo representativos dessa categoria profissional e nem dessa proposta de gestão.

Outra possibilidade seria acompanhar mais de perto os trabalhadores no período inicial. A criação de um espaço de escuta qualificada, a fim de possibilitar a busca de alternativas de enfrentamento do sofrimento psíquico vivenciado nessa etapa, poderia auxiliar na adaptação à proposta do modelo de gestão em pauta.

\section{Referências}

Alves, G. A. P. (2008). A subjetividade às avessas: toyotismo e "captura" da subjetividade do trabalho pelo capital. Cadernos de Psicologia Social do Trabalho, 11(2), 223-239.

Antunes, R (2001). Os sentidos do trabalho: ensaio sobre a afirmação e a negação do trabalho. São Paulo, Boitempo. 
Antunes, R. (2014). Desenhando a nova morfologia do trabalho no Brasil. Estudos Avançados, 28(81), 39-53.

Barbour, R. (2009). Grupos Focais. Artmed: Porto Alegre.

Blond, M., \& Netterstrom, B.(2007). Neuromotor function in a cohort of Danish steel workers. Neurotoxicology, 28(2), 336- 44

Bouchard, M., Mergler, D.,Baldwin, M., Panisset, M., \& Roels, H.A. (2007). Neuropsychiatric symptoms and past manganese exposure in a ferro-alloy plant.Neurotoxicology, 28(2), 290-7.

Bueno, M., \& Macêdo, K. B. (2012). A clínica psicodinâmica do trabalho: de Dejours às pesquisas brasileiras. ECOS, 2(2), 306-318.

Creswell, J. W. (2010). Projeto de pesquisa: métodos qualitativo, quantitativo e misto. Porto Alegre: Artmed.

Dejours, C. (1993). Pour une clinique de lamédiationenrepsychanalise et politique: lapsychodynamiquedutravail. RevueTrans, 131-156.

Dejours, C. (2003). L'évaluation du travail àl'épreuve du réel. Critiques desfondements del'evaluation. Paris: INRAEditions.

Dejours, C. (2004). Subjetividade, trabalho e ação. Produção, 14(3), 27-34.

Diesse (2012). A indústria siderúrgica e da metalurgia básicano Brasil: diagnóstico e propostas elaboradas pelos metalúrgicos da CUT.

Duarte, F. S., \& Mendes, A. M. (2015). Da escravidão à servidão voluntária: perspectivas para a clínica psicodinâmica do trabalho no Brasil. Revista de Estudos Organizacionais e Sociedade, 3, 68-128.

Falco, A., Girardi, D., Marcuzzo, G., De Carlo, A., \& Bartolucci, G. B. (2013). Work stress and negative affectivity: a multi-method study. Occup Med (Lond), 63(5), 341-7.

Fleury, A.,\& Macedo, K. B. (2015). A Clínica psicodinâmica do trabalho: teoria e método. In K.B, Macêdo (Ed.), Diálogo que transforma (pp. 95-134). Goiânia: Ed.PUC Goiás.

Flick, U. (2009). Uma introdução à pesquisa qualitativa. Porto Alegre: Bookman.

Giu, R.T. (2002). Prazer e Sofrimento: Representações Sociais de Profissionais de Recursos Humanos. Rev. Psicologia Ciência e Profissão, 22(4), 86-93.

Giongo, C. R., Monteiro, J. K., \& Sobrosa, G. M. R. (2015). Psicodinâmica do trabalho no Brasil: revisão sistemática da literatura. Temas em Psicologia, 23(4), 803-814. https://dx.doi.org/10.9788/TP2015.4-01

Haviland, A., Burns, R., Gray, W., Ruder, T.,\& Mendeloff, J. (2010). What kinds of injuries do OSHA inspections prevent. Journal of safety research, 41, 339-345.

Heloani, J. R., \& Capitão, C. G. (2003). Saúde mental e psicologia do trabalho. São Paulo em Perspectiva, 17(2), 102-108.

Heloani, R., \& Lancman, S. (2004). Psicodinâmica do trabalho: o método clínico de intervenção e investigação. Revista Produção, 14(3), 77-86. 
Hensing, G., \& Alexanderson, K. (2004). The association between sex segregation, workingconditions, and sickness absence among employed women. Occup Environ Med, 61(2), 1-6.

Hess, R. (1998). Uma técnica de formação e de intervenção: o diário institucional. In R., Hess, \& A. Savoye, (Eds.), Perspectives de I'Analyse Institutionnelle (pp. 119-138). Paris: Méridiens Klincksieck.

Lancman, S., \& Szenelwar, L. (2004). Christophe Dejours: da psicopatologia à psicodinâmica do trabalho (pp.47-104). Rio de Janeiro: Fiocruz/Brasília - Paralelo 15.

Martins, S. R., \& Mendes, A. M. (2012). Espaço coletivo de discussão: a clínica psicodinâmica do trabalho como ação de resistência. Psicologia: Organizações e Trabalho, 12(2), 2436.

Mendes, A. M. (2007). Da psicodinâmica à psicopatologia do trabalho. In A. M. Mendes, (Eds.), Psicodinâmica do Trabalho: teoria, método e pesquisas (pp. 29-48). São Paulo: Casa do Psicólogo.

Mendes, A. M., Costa, V. P., \& Barros, P. C. (2003). Estratégias de enfrentamento do sofrimento psíquico no trabalho bancário. Estudos e Pesquisa em Psicologia, 3(1), 5972.

Mendes, A. M., \& Duarte, F. S. (2013). Mobilização subjetiva. In F. O. Vieira, A. M., Mendes, A. R. C. Merlo (Eds.), Dicionário crítico de gestão e psicodinâmica do trabalho (pp. 259262). Curitiba: Juruá.

Mendes, A. M., \& Vieira, F. O. (2014). Diálogos entre a psicodinâmica e clínica do trabalho e estudos sobre coletivos de trabalho e práticas organizacionais. Rev. De Estudos Organizacionais e Sociedade, 1, 144-189.

Monteiro, J.K., Giongo, C.R., \& Castro, L.S.P. (2015). Clínica do trabalho com trabalhadores rurais: uma escuta necessária. In K.B., Macêdo (Ed.), Diálogo que transforma (pp. 301). Goiânia: Ed.PUC Goiás.

Padula, R. S., Chiavegato, L. D., Cabral, C. M. Almeid, T., Ortiz, T., \& Carregaro, R. L. (2012). Is occupational stress associated with work engagement?Work, 41(1), 2963-5.

Rabe, M., Giacomuzzi, S., \& Nubling, M. (2012). Psychosocial workload and stress in theworkers' representative. BMC Public Health, 12(909), 1-11.

Ramos, L. V., \& Mendes, A. M. (2013) A dinâmica da cooperação entre gestores de uma empresa multinacional. Revista Gestão e Tecnologia, 13(3), 222-246.

Silva, C. A. F. (2008). A gestão de si na reinvenção das normas: práticas e subjetividades no trabalho. Saúde e Sociedade, 17(4), 111-123.

Tuomi, K., Vanhala, S., Nykyri, S., \& Janhonen, M. (2004). Organizational practices, work demands andthe well-being of employees: a follow-up studyin the metal industry and retail trade. Occupational Medicine, 54(2), 115-121 
Vieira, F. O. (2014). "Quem vê cara, não vê coração": aspectos discursivos e eufemísticos da sedução organizacional que disfarçam violência e sofrimento no trabalho. Revista Economia \& Gestão, 14(36), 194-120. 